\title{
Coronary Revascularization in Patients With Stable Coronary Artery Disease: The Role of Imaging
}

\author{
Danilo Neglia ${ }^{1,2 *}$, Natallia Maroz-Vadalazhskaya ${ }^{3}$, Nazario Carrabba ${ }^{4}$ and Riccardo Liga ${ }^{5,6}$ \\ ${ }^{1}$ Cardiovascular Department, Fondazione CNR Regione Toscana G. Monasterio, Pisa, Italy, ${ }^{2}$ Sant'Anna School of Advanced \\ Studies, Pisa, Italy, ${ }^{3}$ Postgraduate Division, Belarusian State Medical University, Minsk, Belarus, ${ }^{4}$ Cardiothoracovascular \\ Department, Careggi Hospital, Florence, Italy, ${ }^{5}$ Cardiothoracic and Vascular Department, University Hospital of Pisa, Pisa, \\ Italy, ${ }^{6}$ Dipartimento di Patologia Chirurgica, Medica, Molecolare e dell'Area Critica, Università di Pisa, Pisa, Italy
}

OPEN ACCESS

Edited by:

Alessia Gimelli,

Gabriele Monasterio Tuscany

Foundation (CNR), Italy

Reviewed by:

Kenichiro Otsuka

Massachusetts General Hospital,

United States

Vikas Prasad,

Universitätsklinikum Ulm, Germany

*Correspondence:

Danilo Neglia

dneglia@ftgm.it

Specialty section:

This article was submitted to

Cardiovascular Imaging,

a section of the journal

Frontiers in Cardiovascular Medicine

Received: 29 May 2021 Accepted: 07 October 2021

Published: 28 October 2021

Citation:

Neglia D, Maroz-Vadalazhskaya N,

Carrabba N and Liga $R$ (2021) Coronary Revascularization in Patients With Stable Coronary Artery Disease: The Role of Imaging.

Front. Cardiovasc. Med. 8:716832.

doi: 10.3389/fcvm.2021.716832
In the last decades, the effective management of some cardiovascular risk factors in the general population has led to a progressive decrease in the prevalence of coronary artery disease (CAD). Nevertheless, coronary heart disease remains the major cause of death in developed and developing countries and chronic coronary syndromes (CCS) are still a major target of utilization of non-invasive cardiac imaging and invasive procedures. Current guidelines recommend the use of non-invasive imaging in patients with CCS to identify subjects at higher risk to be referred for invasive coronary angiography and possible revascularization. These recommendations are challenged by two opposite lines of evidence. Recent trials have somewhat questioned the efficacy of coronary revascularization as compared with optimal medical therapy in CCS. As a consequence the role of imaging in these patients and in in patients with ischemic cardiomyopathy is under debate. On the other hand, real-life data indicate that a consistent proportion of patients undergo invasive procedure and are revascularized without any previous non-invasive imaging characterization. On top of this, the impact of COVID-19 pandemic on the sanitary systems caused a change in the current management of patients with CAD. In the present review we will discuss these conflicting data analyzing the evidence which has been recently accumulated as well as the gaps of knowledge which should still be filled.

Keywords: revascularization, coronary artery disease, cardiac imaging, prognosis, COVID-19

\section{INTRODUCTION}

In the last decades, the prevalence of obstructive coronary artery disease (CAD) and significant myocardial ischemia has been progressively decreasing in stable patients (1-4). As a result of the lower prevalence of disease, the accuracy of most of the currently available diagnostic strategies for the evaluation of patients with chronic coronary syndromes (CCS) has been steadily decreasing. Both non-invasive and invasive tests for the evaluation of (hemodynamically significant) CAD have recently shown a low diagnostic yield $(1,5,6)$. The effective management of some cardiovascular risk factors, such as the promotion of healthy lifestyles and reduction of smoking, widespread use of anti-hypertensive and lipid-lowering treatments may have accounted for this trend. Nevertheless, new risk factors are emerging, such as diabetes, obesity, and metabolic syndrome $(7,8)$ which are, in turn, independently linked to CAD, as well as coronary heart disease (CHD) 
mortality and heart failure (HF). As a result, CHD remains the major cause of death in developed and developing countries (9). Accordingly, accurate strategies are now required to evaluate patients with suspected CAD or heart failure, and to characterize their clinical risk profile as well as the presence and extent of CAD. Efforts should be devoted in identifying those subjects at higher risk of cardiac events who might benefit more from optimal and targeted medical therapy alone or associated with coronary revascularization.

\section{CORONARY REVASCULARIZATION OF OBSTRUCTIVE CAD: IS THAT STILL THE MAJOR GOAL?}

In patients with CCS, consistent evidence has challenged the concept that revascularization might improve prognosis more than optimal medical treatment $(\mathrm{OMT})(10,11)$. The relative lower prevalence of severe disease in current populations as compared with the past $(11,12)$ and the prognostic efficacy of OMT targeted to some established risk determinants of coronary atherosclerosis and/or ischemia (13), could somehow explain these findings. Nevertheless, the established concept that revascularization could improve symptoms and prognosis in patients with obstructive CAD is still guiding clinical practice. Accordingly, referring patients with stable symptoms to invasive coronary angiography (ICA) based only on clinical suspicion and without an objective documentation of inducible myocardial ischemia is still a common choice (14).

Recent publications have shown that the pre-test probability (PTP) figures in the previous "European Society of Cardiology" (ESC) guidelines were grossly overestimated (15). The current ESC guidelines for the management of CCS (3) use updated prediction models, showing values of probability of significant CAD which are around $1 / 3$ of those previously reported, and recommend the preliminary definition of the PTP of disease. In patients with PTP $>15 \%$ non-invasive cardiac imaging is strongly encouraged to detect either "high risk" myocardial ischemia or obstructive CAD before considering invasive procedures. Such recommendations are still based on classical evidence coming from historical observational studies suggesting that "significant ischemia" in the absence of extensive scar would benefit from revascularization (16). This concept has been challenged by recent randomized trials such as the "International Study of Comparative Health Effectiveness with Medical and Invasive Approaches" (ISCHEMIA) trial, in which patients with suspected CAD and moderate-to-severe ischemia were randomized to either an invasive strategy (ICA and revascularization when feasible) plus OMT or a conservative management with OMT alone (11). Over a 5-years follow-up there was no significant difference in event-free survival among the two strategies leading to reconsider the indication to invasive procedures in patients with suspected CAD and moderate-tosevere ischemia. These results were the last of a series of evidence coming from randomized trials progressively downplaying the role of functional testing to stratify the risk and guide the management of contemporary populations of patients with CCS and low prevalence of CAD and low overall risk of future cardiac events $(17,18)$. Despite these evidences $(11,17,18)$ there are also reasons to question the simplistic conclusion that revascularization is useless in patients with documented extensive ischemia.

First, in most of these trials multiple, different and not necessarily equivalent modalities were used for the evaluation of myocardial ischemia $(1,6)$. Second, some relevant patients' categories (i.e., anatomical left main stenosis, proximal LAD stenosis, LV systolic dysfunction, and severe symptoms at baseline) have been excluded from major randomized controlled trials (RCT) on CCS, likely reducing the number of those "high risk" patients who could have benefited more from revascularization. Third, the existence and exact degree of the "specific" burden of ischemia above which revascularization would possibly improve prognosis over OMT is still a matter of intense speculation. According to current clinical guidelines, revascularization should be indicated in patients with an ischemic burden $>10 \%$ of the LV (3). In a recent large observational study, the association between early PCI or CABG (performed $<90$ days from the first evaluation), the ischemic burden and all-cause mortality has been investigated in a large population of patients who underwent single-photon emission computed tomography (SPECT) myocardial perfusion imaging (19). At survival analysis, when patients were stratified according to the extent of ischemia, coronary revascularization (either with PCI or CABG) was associated with decreased mortality in patients with ischemia involving $>15 \%$ of the myocardium. These findings were consistent with prior appraisals (16) and fixed a higher threshold for ischemia severity which might be associated with revascularization benefit.

A final major limitation of these trials was that patient management was not guided by imaging results but left at the discretion of the referring physicians. Thus, the "appropriateness" of coronary revascularization, as defined by treating obstructive $\mathrm{CAD}$ associated with significant downstream ischemia and deferring revascularization in the other cases, could not be determined. In the ISCHEMIA study, ischemia was documented only by stress ECG in almost $25 \%$ of patients (11). Moreover, ICA was complemented by FFR measurements in only $20 \%$ of patients randomized to the invasive strategy (11), while invasive confirmation of the hemodynamic severity of a coronary stenosis by FFR is required by current Guidelines (3). Moreover, other intravascular imaging approaches are increasingly recognized as effective means to guide revascularization procedures (20). As a matter of fact, in a significant percentage of patients the assignment of ischemia to a specific coronary territory could not be possible, and the "appropriateness" of revascularization difficult to be established. In this respect, consistent evidence has been recently accumulating, demonstrating that while "appropriate" revascularization is prognostically beneficial, inappropriate procedures may predispose to adverse cardiac events $(12,20,21)$.

A final consideration applies to the prognostic efficacy of OMT when targeted to the coronary atherosclerotic and 


\section{Imaging STRATEGY to recognize HIGH RISK CAD and guide APPROPRIATE Management}

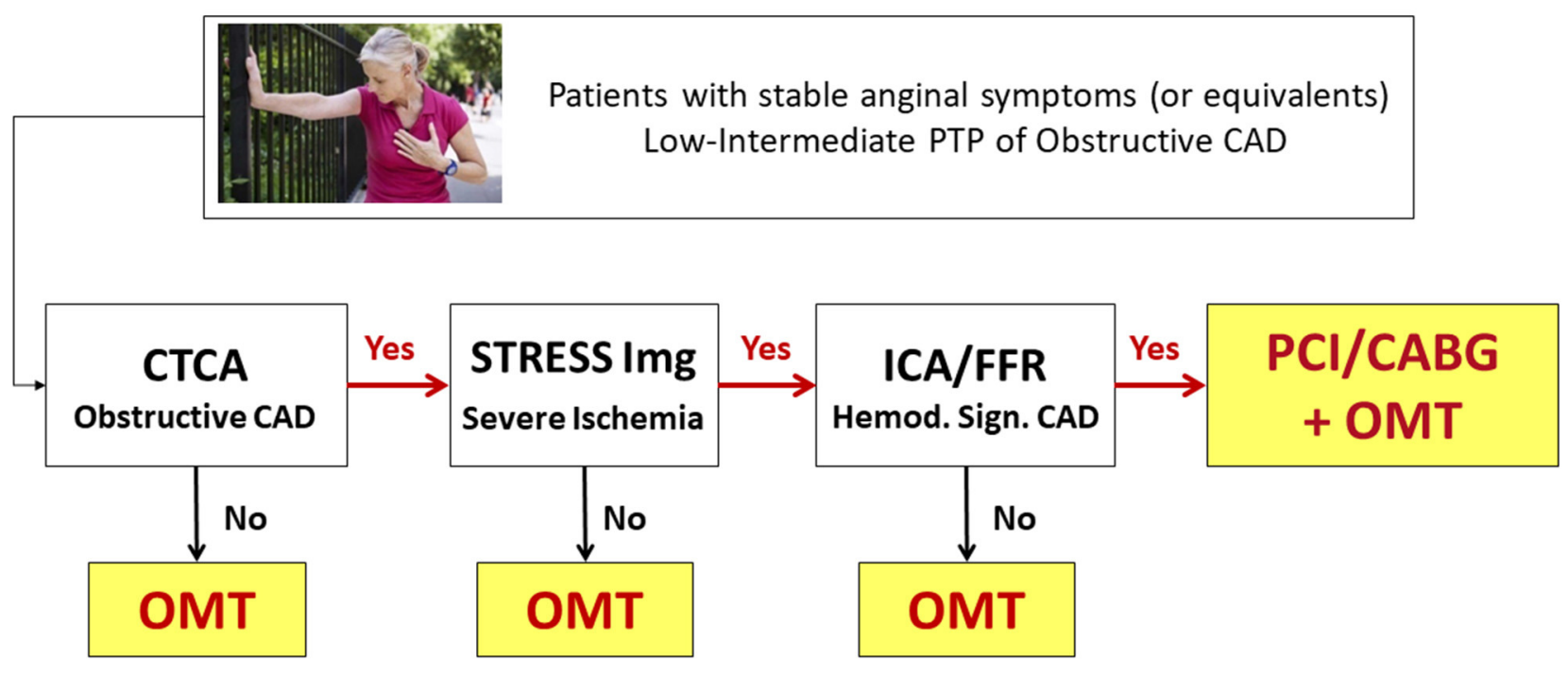

FIGURE 1 | Anatomical and functional imaging integrated strategy to recognize "High Risk" CAD and guide management in patients with low-intermediate PTP of obstructive CAD (see text for details). OMT, Optimal Medical Treatment.

ischemic processes. The diffusion of computed tomography coronary angiography (CTCA) as a first screening test in patients with CCS has increased the recognition of coronary atherosclerosis even in its earlier non-obstructive stages. Including CTCA in the diagnostic process of patients with CCS has been shown to improve outcome as compared to standard of care (18), independently from downstream referral to ICA or revascularization procedures. A possible reason behind these findings is that the evaluation of coronary anatomy with CTCA may allow a better riskstratification of CCS patients than ischemia imaging, possibly unmasking high-risk patients' categories that would be missed by functional techniques. For instance, even in the absence of critical focal lesions, the presence of diffuse non-obstructive CAD may still cause symptoms and myocardial ischemia (22) and may be associated with adverse prognosis, deserving aggressive OMT to prevent future events (23).

In conclusion, current evidence is in favor of an accurate assessment of coronary anatomic and ischemic burden in patients with CCS for risk-stratification and targeting of OMT (3). In patients with obstructive $\mathrm{CAD}$, in whom diameter stenosis $>90 \%$ or severe inducible myocardial ischemia is documented, coronary revascularization on top of OMT might be still the best option, to both control symptoms (24), and possibly improve outcome. The combined assessment of coronary anatomy and myocardial ischemia by an appropriate non-invasive imaging strategy (25-28) may represent the ideal tool for patients' characterization and a gatekeeper to inappropriate invasive procedures (Figure 1).

\section{MANAGEMENT OF PATIENTS WIH STABLE CAD: ROLE OF IMAGING}

The choice of the best diagnostic strategy to be followed in specific categories of patients with CCS is still a matter of debate, given the presence of a limited number of comparative prospective studies in patients with suspected or known CCS. Despite classically considered interchangeable for diagnostic purposes, anatomical and functional imaging techniques allow the assessment of distinct aspects of CAD that are associated with specific risks and may possibly require individualized treatments. Current guidelines in CCS (3) recommend a stepwise evaluation of patients largely based on non-invasive imaging modalities. While CTCA is the reference technique for the assessment of coronary atherosclerosis, stress imaging-either with MPI or wall motion imaging (WMI) - is employed to quantify the burden of inducible myocardial ischemia. Contemporary populations of patients with CCS referred for screening have indeed a lower prevalence of significant CAD than previously expected $(1,29)$, thus candidates to imaging screening should be carefully selected to avoid useless risks and costs. As underlined by current guidelines recommendations, the evaluation of PTP of disease should be integrated with other clinical parameters to better identify patients with intermediate or high likelihood of obstructive CAD who should be submitted to imaging tests $(3,30)$. Accordingly, only patients judged at high risk of future major cardiac events ( $>3 \%$ event-rate per year) after noninvasive imaging assessment should be referred to ICA (3). When a non-invasive imaging test provides an uncertain result a second test is recommended. This is particularly important 
when an anatomical imaging such as CTCA is performed first. The evidence of obstructive CAD (in the absence of left main or three vessel disease and/or proximal LAD obstruction) may be not sufficient to proceed to ICA. The demonstration of significant inducible myocardial ischemia by an additional stress imaging test will better identify those patients who will benefit more from invasive procedures (Figure 1), without forgetting the case of "balanced ischemia," the Achilles heel of stress imaging in case of multivessel CAD (31).

The EVINCI-Outcome study, enrolling patients with stable angina submitted to both CTCA and stress imaging before ICA, provides evidence on the role of imaging to define appropriate treatment and the potential effects on prognosis in a contemporary population of patients with CCS and a low prevalence of disease (30\%) (12). Patients with CAD in whom early revascularization was defined appropriate, because performed in the presence of significant inducible ischaemia and deferred in its absence, had an outcome not significantly different from that of patients without CAD. Conversely, patients with CAD who were revascularized despite no evidence of ischaemia or in whom intervention was deferred despite evidence of ischaemia had approximately a three-fold higher risk of major coronary adverse events than patients with no CAD. Thus, the study results suggested that in a population with low prevalence of significant CAD, a strategy using CTCA as the first test is reasonable. Nevertheless, when anatomical disease is found by CTCA, functional imaging before ICA is necessary to identify those patients with significant inducible ischaemia, who have most to gain by revascularization. In a health-economics analysis of the same study (32) it was shown that combined non-invasive strategies with CTCA and stress imaging are both cost effective as gatekeepers to ICA and to select candidates for early revascularization.

Limited evidence exists on the possible additional role of combined anatomic/functional cardiac imaging in this setting. Nuclear stress imaging tests are well-suited to complement CTCA results also due to their recognized prognostic role $(25,33)$. Integration of functional information from MPI with anatomical description of coronary atherosclerotic disease is easily obtainable in $3 \mathrm{D}$ reconstructions by hybrid SPECT/CT and PET/CT imaging (34). The combination with CTCA performed with new generation scanners and specific acquisition protocols allows obtaining this combined information with an overall radiation dose between 4 and $10 \mathrm{mSv}$, making combined anatomic/functional cardiac imaging an appealing alternative to the classical single-imaging approach. Hybrid imaging, by directly assessing the functional significance of a coronary stenosis holds much promise for future clinical application in better selecting patients for invasive procedures. The clinical value of this approach has been recently explored in the population of the EVINCI trial (25). In this multicenter population of 252 patients with intermediate PTP of CAD, hybrid images have been obtained by 3D fusion of either SPECT/CTCA or PET/CTCA datasets and evaluated by independent observers. The presence of anatomical-functional "match" (inducible perfusion defect downstream an obstructive coronary lesion at CTCA) allowed recognizing significant CAD in $24 \%$ of patients,

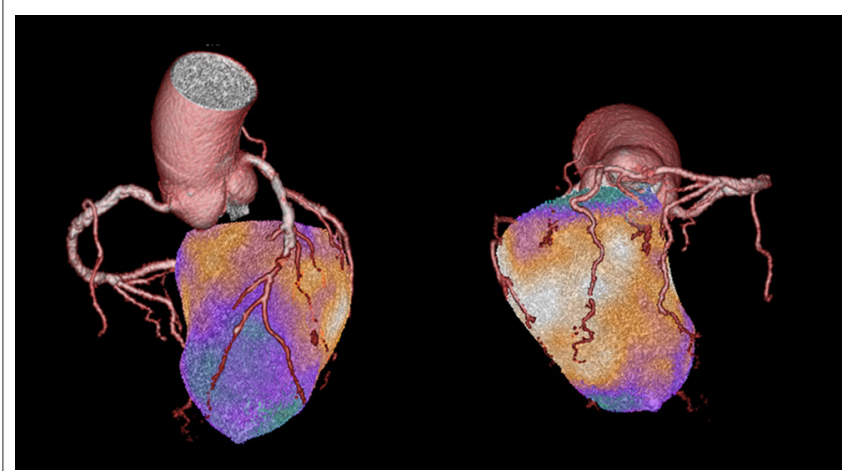

FIGURE 2 | This is a case from the EVINCI Hybrid Imaging cohort (24). A 72-year-old gentleman with atypical chest pain and normal LV systolic function. His pre-test probability of obstructive CAD was 34\%. PET MPI with $\mathrm{H} 2150$ was performed at rest and after adenosine stress, showing the presence of an extensive, entirely reversible, stress-induced perfusion defect involving the LV septum, and the entire apical region. CTCA revealed the presence of multiple significant coronary lesions of the LAD with a sub-total mid occlusion, diffuse atherosclerosis of the LCx, and a significant (50-70\%) stenosis of the mid RCA. On hybrid imaging, the entire perfusion defect was reassigned to the $L A D$, effectively changing the diagnosis from two-vessels to one-vessel disease. Imaging findings were later confirmed by ICA, showing two high-grade lesions in the LAD, and diffuse non-significant atherosclerosis in the other vessels.

while a negative "match" excluded significant CAD in $41 \%$ of patients with an optimal diagnostic accuracy as compared with ICA (PPV $87 \%$ and NPV 88\%). Moreover, because of the $3 \mathrm{D}$ evaluation of coronary anatomy and myocardial perfusion, hybrid imaging also allowed to reallocate perfusion defects to the appropriate coronary territory in $42 \%$ of patients and predicted subsequent revascularizations (Figure 2). These concepts have been further strengthened by recent evidence, indicating the incremental prognostic value of hybrid imaging over CTCA alone $(35,36)$.

An alternative to ischemia testing is the evaluation of the hemodynamic significance of the coronary stenosis at the time of CTCA by means of FFR ${ }_{\mathrm{CT}}(26-28)$. The development of a CTCA-based index represented a relevant step forward to allow a complete anatomical-functional characterization of CAD by a single investigation, possibly reducing the downstream inappropriate referral to invasive coronary angiography (37). In fact, in the last years several studies have reported how the progressive refinements of computational fluid dynamics (CFD) models have brought to a radical increase of $\mathrm{FFR}_{\mathrm{CT}}$ ability in unmasking the presence of invasively assessed hemodynamically significant coronary lesions $(26,27)$. FFR $\mathrm{CT}_{\mathrm{T}}$ seems particularly suited for the investigation of patients with suspected or known CCS, since it provides high accuracy for detection of hemodynamically significant CAD without additional radiation exposure and an improved cost-effectiveness if compared to the standard of care. However, some technical limitations of FFR $_{\mathrm{CT}}$ algorithms should be also acknowledged, including the remote and lengthy core-laboratory analysis currently required for the most tested and validated software. In this context, newest indexes have been proposed to overcome some of the 
limitations of traditional FFR $\mathrm{CT}_{\mathrm{T}}$ algorithms. Among those, virtual functional assessment index (vFAI), derived from the application of computational flow dynamics to standard CCTA datasets, had the main advantage to require a shorter computational time (20-30 min on average) to obtain the results in each case $(28,38) . F^{2} R_{C T}$ has been shown to mimic the results of invasive FFR and to be associated with inducible ischemia detected by stress SPECT $(39,40)$. On the other hand, vFAI has been validated both vs. invasive FFR (38) and against PETderived absolute MBF measurements as integrated measures of global coronary fluid dynamics (28). However, additional research is needed to demonstrate their possible additional role in the diagnostic assessment of patients with CAD. Despite some intrinsic methodological limitations, FFR $_{\mathrm{CT}}$ and vFAI might be an appropriate tool for interrogating the functional significance of a coronary stenosis at CCTA and as a gatekeeper to invasive coronary angiography for revascularization.

Unfortunately, ICA is still commonly used for the diagnosis and to guide treatment without an adequate pre-selection of patients, resulting in high costs, frequent negative invasive studies or revascularization procedures mainly guided by anatomical findings. Moreover, even when stress imaging is performed its results are not fully considered in further management of the patients $(5,25,41)$. Taken together the most recent findings underline the need to perform further trials which could assess the prognostic and cost-effectiveness impact of a management algorithm guided by appropriate combination of anatomical and functional imaging as compared with standard work-up.

Similarly, more research is needed to define whether the role of non-invasive imaging to guide management of patients with stable CAD could be reinforced by the capacity to characterize "high risk" coronary plaque features (42) which carry a relevant prognostic value, independently from the degree of obstruction and the associated ischemia $(43,44)$. Whether the recognition of "vulnerable plaques," promoting a more aggressive medical treatment and/or guiding targeted interventional procedures, could improve outcome is an open research question (45). Moreover, in the near future, the optimal risk stratification and management in the single individual could be improved by a machine learning (ML) approach. A relevant number of imaging variables can be derived automatically and merged with clinical variables obtained by digitalized health records to feed artificial intelligence based decision support systems able to stratify prognosis and guide effective treatment $(46,47)$.

\section{MANAGEMENT OF PATIENTS WITH ISCHEMIC HEART FAILURE: ROLE OF IMAGING}

Ischemic cardiomyopathy (ICM) is generally identified by the presence of significant left ventricular (LV) systolic dysfunction, as defined by LV ejection fraction (EF) lower than 40\%, associated with the presence of extensive CAD (48). While such patients have been almost systematically excluded from the most recent randomized controlled trials on the management of subjects with CCS, complete coronary revascularization is still a class I indication in this population according to current ESC guideline recommendations (49). Most of the evidence favoring revascularisation in patients with ICM derives from old observational studies (50), while weaker evidence comes from RCTs. In particular, the assessment of myocardial viability by non-invasive imaging is still advocated in these patients to decide on the need of coronary revascularization $(3,49,51)$, based on the assumption that in the presence of relevant burden of hibernating myocardium coronary revascularization would result in LV function recovery and lead to a significant prognostic benefit (50). However, also in patients with ICM recent RCT provided conflicting results (52-54).

The Surgical Treatment for Ischaemic Heart Failure (STICH) trial is so far the largest RCT that has evaluated the impact of surgical coronary revascularization in patients with ICM. Of the 1,212 patients enrolled, 610 underwent coronary artery bypass graft $(\mathrm{CABG})$ on top of OMT, while 602 patients were randomized to OMT alone (55). Despite the overall results of the trial were in favor of CABG (death rate $40.5 \%$ with CABG vs. $49.3 \%$ with OMT, $P=0.006$ ), this difference was obtained only after extensive follow-up, because the early increase in mortality related to cardiac surgery was offset by beneficial effects only after $>4$ years. The pre-specified viability sub-study of STICH included the 601 patients with available information on the presence and extent of myocardial viability, as obtained through single-photon emission computed tomography (SPECT) or stress echocardiography $(53,56)$. While patients revascularized despite the absence of significant LV viability had the worst prognosis (overall survival 49 vs. $63 \%$ ), this difference disappeared after correcting for baseline clinical variables (53). However, several major limitations of the study do not allow any conclusive statement on the topic. First, the imaging protocols employed for the assessment of myocardial viability were highly inhomogeneous with, for instance, five different SPECT protocols allowed. Moreover, since patients were not randomized according to the results of viability imaging only indirect evidence on the role of viability imaging in ICM can be inferred. In addition, it is tempting to speculate that the use of more accurate non-invasive imaging modalities, such as cardiac magnetic resonance imaging and positron emission tomography (PET), would have allowed a better characterization and riskstratification of patients, likely translating into improved patients' management and possibly outcome.

The Positron Emission Tomography and Recovery Following Revascularisation (PARR-2) study randomized patients with ischemic heart failure to either a viability-guided management or standard care (52). Myocardial viability was evaluated through fluorodeoxyglucose (FDG) PET imaging and the likelihood of LV function recovery after revascularization was estimated based on the burden of hibernating myocardium. The overall results of the study were neutral, with a similar event-rate in patients randomized to PET imaging as compared to standard care (30 vs. $36 \%, P=0.16)$. However, at further analysis, patients with a more significant burden of hibernating myocardium $(>7 \%$ of the LV) showed a prognostic benefit from coronary revascularization (event-rate 13 vs. $56 \%$ in non-revascularized patients) (57). 
Moreover, when restricting the analysis to patients whose final management was adherent to PET results-revascularized only in the presence of hibernating myocardium and managed conservatively otherwise - a significant prognostic advantage of PET-based treatment was also observed (58).

Available evidence does not allow to make a conclusive statement of the role of viability-guided management in patients with ICM, posing the need of dedicated RCTs on the topic.

\section{CORONARY REVASCULARIZATION AND NON-INVASIVE IMAGING IN THE COVID-19 PANDEMICS}

The management of patients with new onset or worsening symptoms suggestive of CAD has become a challenge for medical personnel and healthcare systems with the worldwide spread of the COVID-19 disease, starting from the end of 2019. As a rule, the normal function of the cardiac catheterization laboratories has been altered to minimize the risk of personnel infection, to preserve hospital beds and to prioritize procedures known to have a higher impact on patients' outcome (59). A national survey among interventional cardiologists in the United States during the COVID-19 pandemic in 2020, identified unprecedented large-scale procedural deferrals, substantially reducing overall activity volumes in the cath-labs (60).

According to available figures, the monthly PCI volumes from March 15 to April 15, 2020 as compared with the same period of 2019 was reduced by 55\% and this reduction was mainly due to deferral of PCI for stable CAD. These data have been most probably also influenced by evidence accumulated from the recent RCTs on the management of patients with CCS, downplaying the role of invasive management. Interestingly, interventional cardiologists perceived that non-invasive imaging studies were $14-24 \%$ more likely to be used to risk stratify patients instead of angiography.

Interventional procedures with immediate mortality benefits, such as primary PCI in STEMI patients, remained prioritized in the hospital protocols (59). Nevertheless, preliminary analysis during the early phase of the COVID pandemic in March 2020 showed an estimated $38 \%$ reduction in U.S. cardiac catheterization laboratory STEMI activations (61), similar to a $40 \%$ reduction noticed in Spain (62), and the almost 50\% reduction observed in Italy, which was paralleled by a substantial increase of the STEMI case fatality rate [risk ratio $(\mathrm{RR})=3.3$, 95\% CI 1.7-6.6; $P<0.001$ ] compared to 2019 (63). While an increase of invasive procedures could have been expected, due to heightened environmental and psychosocial stressors or mimickers such as COVID-19 myopericarditis, the effects of the tendency to avoid medical care due to social distancing or concerns of contracting COVID-19 in the hospital could have prevailed. In an international survey promoted by the ESC in April 2020 on the impact of the COVID-19 pandemic on hospital admissions for cardiovascular emergency, such as STEMI, 80\% of cardiologists (mainly interventional) and cardiovascular nurses felt there had been a decrease in STEMI presentations of at least a $40 \%$ reduction (64) (see the case presented in Figure 3).
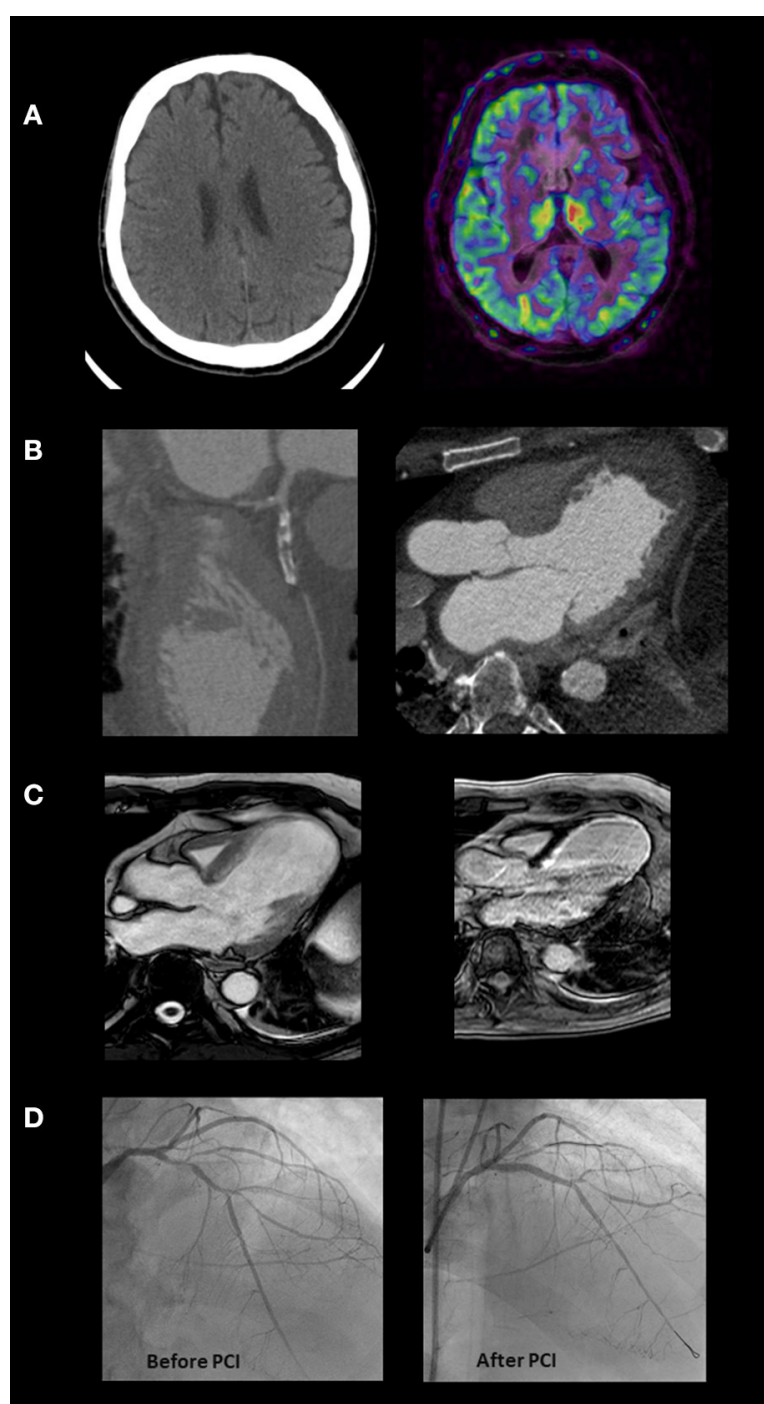

FIGURE 3 | This is the case of a 64-year-old man admitted to the emergency department with symptoms of nausea and vomiting. He reported onset of chest pain and dyspnea 10 days before, during the COVID-19 lock-down. The ECG showed signs of an evolving anterior STEMI. The skull CT (A) evidenced limited left ischemic stroke and large left hygromatous flap. The CCTA (B) demonstrates an occluded proximal left anterior descending (LAD) coronary artery, a large apical aneurysm of the left ventricle and an apical thrombus. Considering the bleeding risk associated with dual antiplatelet therapy and heparin and the need to better define residual viability, invasive coronary angiography (ICA) was deferred starting oral anticoagulation. Apical thrombus was no more evident at cardiac MRI, performed 3 weeks later (C). The exam showed a severe left ventricular dysfunction (LVEF 28\%), and an extensive but not transmural scar in the territory supplied by the LAD. Based on this evidence, after 3 weeks more, the patient underwent ICA confirming LAD disease which was treated by $\mathrm{PCl}$ and drug eluting stenting (D). Before hospital discharge the implantation of an ICD was planned but unfortunately a sudden cardiac death occurred soon after.

The reduction in coronary revascularizations was mirrored by the drop in the use of non-invasive diagnostic procedures in patients with suspected CAD during the COVID-19 pandemics. In a worldwide survey assessing alterations in cardiovascular 
diagnostic procedure volumes and safety practices resulting from COVID-19, non-invasive and invasive cardiac testing volumes were obtained from participating sites for March and April 2020 and compared with those from March 2019 (65). Overall diagnostic procedure volumes decreased 64\% from March 2019 to April 2020. Stress tests in patients with suspected CAD decreased by $78 \%$, with slightly higher decrease for stress electrocardiography (84\%) and echocardiography (83\%) than for nuclear $(73 \%)$ or CMR $(72 \%)$ stress tests. Coronary angiography (invasive or computed tomography) decreased by $55 \%$. Significantly greater reduction in procedures occurred for centers in countries with lower gross domestic product. Location in a low-income and lower-middle-income country was associated with an additional $22 \%$ reduction in cardiac procedures and less availability of personal protective equipment and telehealth.

International scientific societies, such as the European Association of Cardiovascular imaging of the ESC, issued recommendation on cardiac imaging during the COVID-19 pandemic with special attention on indications and prioritization (66). The general indications were that cardiac imaging should have been performed if appropriate and only if it is likely to substantially change patient management or be lifesaving and the imaging modality should be selected taking into consideration safety of both the patients and sanitary staff (67). Moreover, elective or follow-up exams might have been postponed. In this context, CTCA may offer specific advantages in patients with COVID-19 infection and elevated troponins for excluding or confirming CAD, substituting ICA (which has a higher associated exposure of all the members of the cardiac catheterization laboratory team). Moreover, CTCA can be considered in the COVID-19 pandemic in patients with chronic coronary syndromes and severe symptoms. Indications for stress echocardiography, as well as for other stress imaging techniques, are considered very limited in the COVID-19 pandemic and are recommended to be avoided in patients with acute infection. In these patients again coronary CTCA should be the preferred.

Dedicated studies will be warranted to assess whether some of the relevant changes in care delivery related with COVID-19 will

\section{REFERENCES}

1. Neglia D, Rovai D, Caselli C, Pietila M, Teresinska A, Aguadé-Bruix $\mathrm{S}$, et al. Detection of significant coronary artery disease by noninvasive anatomical and functional imaging. Circ Cardiovasc Imaging. (2015) 8:e02179. doi: 10.1161/CIRCIMAGING.114.002179

2. Jouni H, Askew JW, Crusan DJ, Miller TD, Gibbons RJ. Temporal trends of single-photon emission computed tomography myocardial perfusion imaging in patients with coronary artery disease: a 22-year experience from a Tertiary Academic Medical Center. Circ Cardiovasc Imaging. (2017) 10:e005628. doi: 10.1161/CIRCIMAGING.116.005628

3. Knuuti J, Wijns W, Saraste A, Capodanno D, Barbato E, FunckBrentano C, et al. 2019 ESC Guidelines for the diagnosis and management of chronic coronary syndromes. Eur Heart J. (2020) 41:407-77. doi: 10.1093/eurheartj/ehz425

4. Rozanski A, Gransar H, Hayes SW, Min J, Friedman JD, Thomson LEJ, et al. Temporal trends in the frequency of inducible myocardial ischemia last even after the pandemic period and whether these changes had an impact on cardiovascular outcomes.

\section{CONCLUSIONS}

In the last decades, the role of coronary revascularization in patients with CCS has been progressively challenged. In this setting, non-invasive cardiac imaging, aiming at evaluating the presence of obstructive CAD and/or the extent of myocardial ischemic burden, is still recommended to identify individuals who might benefit more from an invasive management. Recent data have underlined the role of a sequential anatomical and functional diagnostic strategy to guide selective coronary revascularization and improve clinical outcome. This approach might be particularly suited in patients with ICM, in whom the risks of revascularization procedures are increased, and more targeted interventions are needed. Real-life data indicate, on the other hand, that a consistent proportion of patients undergo ICA and ultimately coronary revascularization without any previous characterization and proof of inducible myocardial ischemia, leading to inappropriate resources utilization and possibly a higher complications rate. During the COVID-19 pandemic the sanitary systems have been forced to reduce non-urgent interventional procedures including coronary revascularizations. While some useless procedures could have been avoided, there is clear evidence that unwanted delays have been accumulated in treating patients at high risk. This experience will probably further help to reconsider the effectiveness of current management of patients with CAD and prompt new trials to define the role of imaging guided revascularization vs. OMT.

\section{AUTHOR CONTRIBUTIONS}

DN, NM-V, NC, and RL contributed to conception of the review. DN wrote the first draft of the manuscript. NM-V, NC, and $\mathrm{RL}$ wrote sections of the manuscript. RL assembled the final version. All authors contributed to manuscript revision, read, and approved the submitted version. during cardiac stress testing: 1991 to 2009. J Am Coll Cardiol. (2013) 61:105465. doi: 10.1016/j.jacc.2012.11.056

5. Patel MR, Peterson ED, Dai D, Brennan JM, Redberg RF, Anderson $\mathrm{HV}$, et al. Low diagnostic yield of elective coronary angiography. $N$ Engl J Med. (2010) 362:886-95. doi: 10.1056/NEJMoa09 07272

6. Danad I, Raijmakers PG, Driessen RS, Leipsic J, Raju R, Naoum C, et al. Comparison of coronary CT angiography, SPECT, PET, and hybrid imaging for diagnosis of ischemic heart disease determined by fractional flow reserve. JAMA Cardiol. (2017) 2:1100-7. doi: 10.1001/jamacardio.2017.2471

7. Sperling LS, Mechanick JI, Neeland IJ, Herrick CJ, Després JP, Ndumele $\mathrm{CE}$, et al. The cardiometabolic health alliance: working toward a new care model for the metabolic syndrome. J Am Coll Cardiol. (2015) 66:105067. doi: 10.1016/j.jacc.2015.06.1328

8. Piché ME, Tchernof A, Després JP. Obesity phenotypes, diabetes, and cardiovascular diseases. Circ Res. (2020) 126:1477500. doi: 10.1161/CIRCRESAHA.120.316101 
9. Timmis A, Townsend N, Gale CP, Torbica A, Lettino M, Petersen SE, et al. European Society of cardiology: cardiovascular disease statistics 2019. Eur Heart J. (2020) 41:12-85. doi: 10.1093/eurheartj/ehz859

10. Boden WE, O’Rourke RA, Teo KK, Hartigan PM, Maron DJ, Kostuk WJ, et al. Optimal medical therapy with or without PCI for stable coronary disease. $N$ Engl J Med. (2007) 356:1503-16. doi: 10.1056/NEJMoa070829

11. Maron DJ, Hochman JS, Reynolds HR, Bangalore S, O'Brien SM, Boden WE, et al. Initial invasive or conservative strategy for stable coronary disease. $N$ Engl J Med. (2020) 382:1395-407. doi: 10.1056/NEJMoa1915922

12. Neglia D, Liga R, Caselli C, Carpeggiani C, Lorenzoni V, Sicari R, et al. Anatomical and functional coronary imaging to predict long-term outcome in patients with suspected coronary artery disease: the EVINCI-outcome study. Eur Heart J Cardiovasc Imaging. (2019) 21:1273-82. doi: 10.1093/ehjci/jez248

13. Adamson PD, Williams MC, Dweck MR, Mills NL, Boon NA, Daghem M, et al. Guiding therapy by coronary CT angiography improves outcomes in patients with stable chest pain. J Am Coll Cardiol. (2019) 74:205870. doi: 10.1016/j.jacc.2019.07.085

14. Parikh RV, Liu G, Plomondon ME, Sehested TSG, Hlatky MA, Waldo SW, et al. Utilization and outcomes of measuring fractional flow reserve in patients with stable ischemic heart disease. J Am Coll Cardiol. (2020) 75:409-19. doi: 10.1016/j.jacc.2019.10.060

15. Baskaran L, Danad I, Gransar H, Ó Hartaigh B, Schulman-Marcus J, Lin FY, et al. A comparison of the updated diamond-forrester, CAD consortium, and CONFIRM history-based risk scores for predicting obstructive coronary artery disease in patients with stable chest pain: the SCOT-HEART coronary CTA cohort. JACC Cardiovasc Imaging. (2019) 12:1392-400. doi: 10.1016/j.jcmg.2018.02.020

16. Hachamovitch R, Rozanski A, Shaw LJ, Stone GW, Thomson LE, Friedman JD, et al. Impact of ischaemia and scar on the therapeutic benefit derived from myocardial revascularization vs. medical therapy among patients undergoing stress-rest myocardial perfusion scintigraphy. Eur Heart J. (2011) 32:101224. doi: 10.1093/eurheartj/ehq500

17. Hoffmann U, Ferencik M, Udelson JE, Picard MH, Truong QA, Patel MR, et al. Prognostic value of noninvasive cardiovascular testing in patients with stable chest pain: insights from the PROMISE Trial (Prospective Multicenter Imaging Study for Evaluation of Chest Pain). Circulation. (2017) 135:232032. doi: 10.1161/CIRCULATIONAHA.116.024360

18. SCOT-HEART Investigators, Newby DE, Adamson PD, Berry C, Boon NA, Dweck MR, et al. Coronary CT angiography and 5-year risk of myocardial infarction. N Engl J Med. (2018) 379:924-33. doi: 10.1056/NEJMoa1805971

19. Miller RJH, Bonow RO, Gransar H, Park R, Slomka PJ, Friedman JD, et al. Percutaneous or surgical revascularization are associated with survival benefit in stable coronary artery disease. Eur Heart J Cardiovasc Imaging. (2020) 21:961-70. doi: 10.1093/ehjci/jeaa083

20. Buccheri S, Franchina G, Romano S, Puglisi S, Venuti G, D'Arrigo P, et al. Clinical outcomes following intravascular imaging-guided versus coronary angiography-guided percutaneous coronary intervention with stent implantation: a systematic review and Bayesian network meta-analysis of 31 studies and 17,882 patients. JACC Cardiovasc Interv. (2017) 10:248898. doi: 10.1016/j.jcin.2017.08.051

21. Xaplanteris P, Fournier S, Pijls NHJ, Fearon WF, Barbato E, Tonino PAL, et al. Five-year outcomes with PCI guided by fractional flow reserve. N Engl J Med. (2018) 379:250-9. doi: 10.1056/NEJMoa1803538

22. Liga R, Marini C, Coceani M, Filidei E, Schlueter M, Bianchi M, et al. Structural abnormalities of the coronary arterial wall-in addition to luminal narrowing-affect myocardial blood flow reserve. J Nucl Med. (2011) 52:170412. doi: 10.2967/jnumed.111.091009

23. Williams MC, Moss AJ, Dweck M, Adamson PD, Alam S, Hunter A, et al. Coronary artery plaque characteristics associated with adverse outcomes in the SCOT-HEART study. J Am Coll Cardiol. (2019) 73:291301. doi: 10.1016/j.jacc.2018.10.066

24. Spertus JA, Jones PG, Maron DJ, O’Brien SM, Reynolds HR, Rosenberg Y, et al. Health-status outcomes with invasive or conservative care in coronary disease. N Engl J Med. (2020) 382:1408-19. doi: 10.1056/NEJMoa1916370

25. Liga R, Vontobel J, Rovai D, Marinelli M, Caselli C, Pietila M, et al. Multicentre multi-device hybrid imaging study of coronary artery disease: results from the EValuation of INtegrated Cardiac Imaging for the Detection and Characterization of Ischaemic Heart Disease (EVINCI) hybrid imaging population. Eur Heart J Cardiovasc Imaging. (2016) 17:95160. doi: 10.1093/ehjci/jew038

26. Min JK, Leipsic J, Pencina MJ, Berman DS, Koo BK, van Mieghem A, et al. Diagnostic accuracy of fractional flow reserve from anatomic CT angiography. JAMA. (2012) 308:1237-45. doi: 10.1001/2012.jama.11274

27. Douglas PS, De Bruyne B, Pontone G, Patel MR, Norgaard BL, Byrne RA, et al. 1-year outcomes of FFRCT-guided care in patients with suspected coronary disease: the PLATFORM study. J Am Coll Cardiol. (2016) 68:43545. doi: 10.1016/j.jacc.2016.05.057

28. Anagnostopoulos CD, Siogkas PK, Liga R, Benetos G, Maaniitty T, Sakellarios $\mathrm{AI}$, et al. Characterization of functionally significant coronary artery disease by a coronary computed tomography angiography-based index: a comparison with positron emission tomography. Eur Heart J Cardiovasc Imaging. (2019) 20:897-905. doi: 10.1093/ehjci/jey199

29. Douglas PS, Hoffmann U, Patel MR, Mark DB, Al-Khalidi HR, Cavanaugh B, et al. Outcomes of anatomical versus functional testing for coronary artery disease. N Engl J Med. (2015) 372:1291-300. doi: 10.1056/NEJMoa1415516

30. Juarez-Orozco LE, Saraste A, Capodanno D, Prescott E, Ballo H, Bax JJ, et al. Impact of a decreasing pre-test probability on the performance of diagnostic tests for coronary artery disease. Eur Heart J Cardiovasc Imaging. (2019) 20:1198-207. doi: 10.1093/ehjci/jez054

31. Ghadri JR, Pazhenkottil AP, Nkoulou RN, Goetti R, Buechel RR, Husmann $\mathrm{L}$, et al. Very high coronary calcium score unmasks obstructive coronary artery disease in patients with normal SPECT MPI. Heart. (2011) 97:9981003. doi: 10.1136/hrt.2010.217281

32. Lorenzoni V, Bellelli S, Caselli C, Knuuti J, Underwood SR, Neglia D, et al. Cost-effectiveness analysis of stand-alone or combined noninvasive imaging tests for the diagnosis of stable coronary artery disease: results from the EVINCI study. Eur J Health Econ. (2019) 20:143749. doi: 10.1007/s10198-019-01096-5

33. Gaemperli O, Saraste A, Knuuti J. Cardiac hybrid imaging. Eur Heart J Cardiovasc Imaging. (2012) 13:51-60. doi: 10.1093/ejechocard/jer240

34. Flotats A, Knuuti J, Gutberlet M, Marcassa C, Bengel FM, Kaufmann PA, et al. Hybrid cardiac imaging: SPECT/CT and PET/CT. A joint position statement by the European Association of Nuclear Medicine (EANM), the European Society of Cardiac Radiology (ESCR) and the European Council of Nuclear Cardiology (ECNC). Eur J Nucl Med Mol Imaging. (2011) 38:20112. doi: $10.1007 / \mathrm{s} 00259-010-1586-y$

35. Pazhenkottil AP, Nkoulou RN, Ghadri JR, Herzog BA, Buechel RR, Küest SM, et al. Prognostic value of cardiac hybrid imaging integrating single-photon emission computed tomography with coronary computed tomography angiography. Eur Heart J. (2011) 32:1465-71. doi: 10.1093/eurheartj/ehr047

36. Maaniitty T, Stenström I, Bax JJ, Uusitalo V, Ukkonen H, Kajander S, et al. Prognostic value of coronary CT angiography with selective PET perfusion imaging in coronary artery disease. JACC Cardiovasc Imaging. (2017) 10:136170. doi: 10.1016/j.jcmg.2016.10.025

37. Curzen NP, Nolan J, Zaman AG, Nørgaard BL, Rajani R. Does the routine availability of CT-derived FFR influence management of patients with stable chest pain compared to CT angiography alone?: the FFRCT RIPCORD Study. JACC Cardiovasc Imaging. (2016) 9:1188-94. doi: 10.1016/j.jcmg.2015.12.026

38. Siogkas PK, Anagnostopoulos CD, Liga R, Exarchos TP, Sakellarios AI, Rigas $\mathrm{G}$, et al. Noninvasive CT-based hemodynamic assessment of coronary lesions derived from fast computational analysis: a comparison against fractional flow reserve. Eur Radiol. (2019) 29:2117-26. doi: 10.1007/s00330-018-5781-8

39. Gonzalez JA, Lipinski MJ, Flors L, Shaw PW, Kramer CM, Salerno M. Meta-analysis of diagnostic performance of coronary computed tomography angiography, computed tomography perfusion, and computed tomographyfractional flow reserve in functional myocardial ischemia assessment versus invasive fractional flow reserve. Am J Cardiol. (2015) 116:146978. doi: 10.1016/j.amjcard.2015.07.078

40. Nakanishi R, Osawa K, Ceponiene I, Huth G, Cole J, Kim M, et al. The diagnostic performance of SPECT-MPI to predict functional significant coronary artery disease by fractional flow reserve derived from CCTA (FFRCT): sub-analysis from ACCURACY and VCT001 studies. Int $J$ Cardiovasc Imaging. (2017) 33:2067-72. doi: 10.1007/s10554-017-1207-y

41. Hachamovitch R, Nutter B, Hlatky MA, Shaw LJ, Ridner ML, Dorbala S, et al. Patient management after noninvasive cardiac imaging results from SPARC (Study of myocardial perfusion and coronary anatomy imaging 
roles in coronary artery disease). J Am Coll Cardiol. (2012) 59:46274. doi: 10.1016/j.jacc.2011.09.066

42. Giannopoulos AA, Benz DC, Gräni C, Buechel RR. Imaging the event-prone coronary artery plaque. J Nucl Cardiol. (2019) 26:141-53. doi: 10.1007/s12350-017-0982-0

43. Otsuka K, Fukuda S, Tanaka A, Nakanishi K, Taguchi H, Yoshikawa J, et al. Napkin-ring sign on coronary CT angiography for the prediction of acute coronary syndrome. JACC Cardiovasc Imaging. (2013) 6:44857. doi: 10.1016/j.jcmg.2012.09.016

44. Lee JM, Choi KH, Koo BK, Park J, Kim J, Hwang D, et al. Prognostic implications of plaque characteristics and stenosis severity in patients with coronary artery disease. J Am Coll Cardiol. (2019) 21:2413-24. doi: 10.1016/j.jacc.2019.02.060

45. Stone GW, Maehara A, Ali ZA, Held C, Matsumura M, Kjøller-Hansen L, et al. Percutaneous coronary intervention for vulnerable coronary atherosclerotic plaque. J Am Coll Cardiol. (2020) 76:2289-301. doi: 10.1016/j.jacc.2020.09.547

46. Hu LH, Betancur J, Sharir T, Einstein AJ, Bokhari S, Fish MB, et al. Machine learning predicts per-vessel early coronary revascularization after fast myocardial perfusion SPECT: results from multicentre REFINE SPECT registry. Eur Heart J Cardiovasc Imaging. (2020) 21:549-59. doi: 10.1093/ehjci/jez177

47. Rios R, Miller RJH, Hu LH, Otaki Y, Singh A, Diniz M, et al. Determining a minimum set of variables for machine learning cardiovascular event prediction: results from REFINE SPECT registry. Cardiovasc Res. (2021). doi: 10.1093/cvr/cvab236. [Epub ahead of print].

48. Cabac-Pogorevici I, Muk B, Rustamova Y, Kalogeropoulos A, Tzeis S, Vardas P. Ischaemic cardiomyopathy. Pathophysiological insights, diagnostic management and the roles of revascularisation and device treatment. Gaps and dilemmas in the era of advanced technology. Eur J Heart Failure. (2020) 22:789-99. doi: 10.1002/ejhf.1747

49. Neumann FJ, Sousa-Uva M, Ahlsson A, Alfonso F, Banning AP, Benedetto U, et al. 2018 ESC/EACTS Guidelines on myocardial revascularization. Eur Heart J. (2019) 40:87-165. doi: 10.1093/eurheartj/ehy394

50. Ling LF, Marwick TH, Flores DR, Jaber WA, Brunken RC, Cerqueira $\mathrm{MD}$, et al. Identification of therapeutic benefit from revascularization in patients with left ventricular systolic dysfunction: inducible ischemia versus hibernating myocardium. Circ Cardiovasc Imaging. (2013) 6:36372. doi: 10.1161/CIRCIMAGING.112.000138

51. Ponikowski P, Voors AA, Anker SD, Bueno H, Cleland JGF, Coats AJS, et al. 2016 ESC Guidelines for the diagnosis and treatment of acute and chronic heart failure: the Task Force for the diagnosis and treatment of acute and chronic heart failure of the European Society of Cardiology (ESC) Developed with the special contribution of the Heart Failure Association (HFA) of the ESC. Eur Heart J. (2016) 37:2129-200. doi: 10.1093/eurheartj/ehw128

52. Beanlands RS, Nichol G, Huszti E, Humen D, Racine N, Freeman M, et al. F-18-fluorodeoxyglucose positron emission tomography imaging-assisted management of patients with severe left ventricular dysfunction and suspected coronary disease: a randomized, controlled trial (PARR-2). J Am Coll Cardiol. (2007) 50:2002-12. doi: 10.1016/j.jacc.2007.09.006

53. Bonow RO, Maurer G, Lee KL, Holly TA, Binkley PF, Desvigne-Nickens P, et al. Myocardial viability and survival in ischemic left ventricular dysfunction. N Engl J Med. (2011) 364:1617-25. doi: 10.1056/NEJMoal100358

54. Cleland JG, Calvert M, Freemantle N, Arrow Y, Ball SG, Bonser RS, et al. The Heart Failure Revascularisation Trial (HEART). Eur J Heart Fail. (2011) 13:227-33. doi: 10.1093/eurjhf/hfq230

55. Velazquez EJ, Lee KL, Jones RH, Al-Khalidi HR, Hill JA, Panza JA, et al. Coronary-artery bypass surgery in patients with ischemic cardiomyopathy. $N$ Engl J Med. (2016) 374:1511-20. doi: 10.1056/NEJMoa1602001

56. Bonow RO, Castelvecchio S, Panza JA, Berman DS, Velazquez EJ, Michler RE, et al. Severity of remodeling, myocardial viability, and survival in ischemic LV dysfunction after surgical revascularization. JACC Cardiovasc Imaging. (2015) 8:1121-9. doi: 10.1016/j.jcmg.2015.03.013

57. D'Egidio G, Nichol G, Williams KA, Guo A, Garrard L, deKemp R, et al. Increasing benefit from revascularization is associated with increasing amounts of myocardial hibernation: a substudy of the PARR-2 trial. JACC Cardiovasc Imaging. (2009) 2:1060-8. doi: 10.1016/j.jcmg.2009.02.017

58. Mc Ardle B, Shukla T, Nichol G, deKemp RA, Bernick J, Guo A, et al. Long-Term follow-up of outcomes with F-18-fluorodeoxyglucose positron emission tomography imaging-assisted management of patients with severe left ventricular dysfunction secondary to coronary disease. Circ Cardiovasc Imaging. (2016) 9:e004331. doi: 10.1161/CIRCIMAGING.115.004331

59. Welt FGP, Shah PB, Aronow HD, Bortnick AE, Henry TD, Sherwood MW, et al. American College of Cardiology's Interventional Council and the Society for Cardiovascular Angiography and Interventions. Catheterization Laboratory Considerations during the Coronavirus (COVID-19) Pandemic: from the ACC's Interventional Council and SCAI. J Am Coll Cardiol. (2020) 75:2372-5. doi: 10.1016/j.jacc.2020.03.021

60. Yong CM, Ang L, Welt FGP, Gummidipundi S, Henry TD, Pinto DS, et al. Society for Cardiovascular Angiography and Interventions (SCAI) and the American College of Cardiology (ACC) Interventional Council. Cardiac procedural deferral during the coronavirus (COVID-19) pandemic. Catheter Cardiovasc Interv. (2020) 96:1080-6. doi: 10.1002/ccd.29262

61. Garcia S, Albaghdadi MS, Meraj PM, Schmidt C, Garberich R, Jaffer FA, et al. Reduction in ST-Segment elevation cardiac catheterization laboratory activations in the United States during COVID-19 pandemic. J Am Coll Cardiol. (2020) 75:2871-2. doi: 10.1016/j.jacc.2020.04.011

62. Rodríguez-Leor O, Cid-Álvarez B, Ojeda S, Martín-Moreiras J, Ramón Rumoroso J, López-Palop R, et al. Impacto de la pandemia de COVID-19 sobre la actividad asistencial en cardiología intervencionista en España. REC Interv Cardiol. (2020). 2:82-9. doi: 10.24875/RECIC.M20000120

63. Rodríguez-Leor O, Cid-Álvarez B, Pérez de Prado A, Rossello X, Ojeda S, Serrador A, et al. Impact of COVID-19 on ST-segment elevation myocardial infarction care. The Spanish experience. Rev Esp Cardiol (Engl Ed). (2020) 73:994-1002. doi: 10.1016/j.rec.2020.08.002

64. De Rosa S, Spaccarotella C, Basso C, Calabrò MP, Curcio A, Filardi PP, et al. Reduction of hospitalizations for myocardial infarction in Italy in the COVID-19 era. Eur Heart J. (2020) 41:2083-8. doi: 10.1093/eurheartj/ehaa409

65. Pessoa-Amorim G, Camm CF, Gajendragadkar P, De Maria GL, Arsac C, Laroche $\mathrm{C}$, et al. Admission of patients with STEMI since the outbreak of the COVID-19 pandemic: a survey by the European Society of Cardiology. Eur Hert J Qual Care Clin Outcomes. (2020) 6:210-6. doi: 10.1093/ehjqcco/qcaa046

66. Einstein AJ, Shaw LJ, Hirschfeld C, Williams MC, Villines TC, Better N, et al. International impact of COVID-19 on the diagnosis of heart disease. J Am Coll Cardiol. (2021) 77:173-85. doi: 10.1016/j.jacc.2020.10.054

67. Skulstad H, Cosyns B, Popescu BA, Galderisi M, Salvo GD, Donal E, et al. COVID-19 pandemic and cardiac imaging: EACVI recommendations on precautions, indications, prioritization, and protection for patients and healthcare personnel. Eur Heart J Cardiovasc Imaging. (2020) 21:5928. doi: 10.1093/ehjci/jeaa072

Conflict of Interest: The authors declare that the research was conducted in the absence of any commercial or financial relationships that could be construed as a potential conflict of interest.

Publisher's Note: All claims expressed in this article are solely those of the authors and do not necessarily represent those of their affiliated organizations, or those of the publisher, the editors and the reviewers. Any product that may be evaluated in this article, or claim that may be made by its manufacturer, is not guaranteed or endorsed by the publisher.

Copyright (๑) 2021 Neglia, Maroz-Vadalazhskaya, Carrabba and Liga. This is an open-access article distributed under the terms of the Creative Commons Attribution License (CC BY). The use, distribution or reproduction in other forums is permitted, provided the original author(s) and the copyright owner(s) are credited and that the original publication in this journal is cited, in accordance with accepted academic practice. No use, distribution or reproduction is permitted which does not comply with these terms. 